\title{
Discussion on Improving the Quality of Clinical Teaching in Rehabilitation Treatment Specialty
}

\author{
Cai-Ling REN \\ Gannan Medical University, Ganzhou 341000, Jiangxi Province, China. \\ rlingz@163.com
}

Keywords: Rehabilitation, Clinical teaching, Teaching quality.

\begin{abstract}
In the "people-oriented" service concept focusing on the teaching measures in the teaching process of the implementation, and strengthen the construction of teaching staff, improve the teaching management system, to ensure that the teaching measures, strengthen the quality of clinical teaching of professional rehabilitation, promote the students' future to become a qualified therapist.
\end{abstract}

Clinical teaching activities of rehabilitation therapy major is an important part of school teaching activities. Clinical teaching activities refer to the organization under the guidance of clinical teachers. It is an important way to improve the students' clinical operation level to engage in various clinical medical and nursing work planned in higher medical school. The quality of teaching is directly related to the actual work ability of the students after graduation, the future of students and the life and health of patients. Therefore, as a medical education worker. It is an important measure to train new medical talents to improve their clinical teaching level.

\section{Establish a "People-Oriented" Service Concept}

As future rehabilitation therapists, students majoring in rehabilitation therapy should first of all set up the service concept of "people-oriented"[1]. In order to cultivate their own noble medical ethics and exquisite technology, to establish a "people-oriented" service concept is to establish a good relationship between doctors and patients, is to achieve the early recovery of patients, in the field of medicine. There are two main connotations in the teaching idea of "text with people": first, taking students as the center, realizing the students' all-round development under the premise of obeying the students' characteristics and character as far as possible; Second, in the clinical teaching of rehabilitation medicine, students should be trained to take the patient as the center. In clinical work, patients' wishes and rights should be respected to help them get rid of disease. In order to achieve the above two points, students should not only be able to master the basic medical knowledge, basic theory and basic skills. In addition, the school should create a "people-oriented" teaching environment for students, and cultivate students to have a benevolent heart in the invisible.

\section{Pay Attention to the Implementation of All Kinds of Teaching in the Teaching Process}

\section{Training Students in Problem Analysis and Problem-Solving Skills}

The significance of rehabilitation clinical teaching practice lies in cultivating students' ability to find and solve problems. A discussion group based on cases can be used in clinical teaching to allow students to sum up clinical practice. Constantly consult the relevant information to discuss the relevant cases, express their own views, and summarize and improve. Finally, each group elected a representative to make concluding remarks. This teaching method not only improves the enthusiasm of students to participate in learning, but also exercises the students' ability of language expression. For the future to establish a good relationship between doctors and patients lay a solid foundation.

\section{Strengthen the Training of Students' Rehabilitation Skills and Operational Skills}

According to the students in different departments for proper training of students operating skills. 
For entering the clinical rehabilitation teaching students should first choose some rich teaching experience of teachers' operation demonstration, for example[2]: how to assess how ADL ROM, how to carry out the assessment, physical therapy and so on, let the students have a preliminary understanding for rehabilitation. For students, but also can allow students to let the students in the teachers led to personally participate in the rehabilitation process of patients, increase their rehabilitation of basic skills training.

\section{Strengthen the Communication between Teaching and Learning}

In clinical rehabilitation teaching, clinical practice is the main work, especially to strengthen the theoretical basis for students. Basic knowledge and basic ability of the comprehensive training to achieve the correct use of theoretical knowledge in clinical practice. At the beginning of clinical practice, some students may learn because of the content. The methods of learning, the learning environment and the role of learning cannot adapt to the new environment, showing isolation in clinical practice. Unwilling to communicate with classmates and teachers. For such typical problems, the leaders of medical colleges and universities, interns and teachers should The special session should be discussed, through the school seminars, exchange meetings and other timely grasp of students in clinical doubt, and to take effective measures against students' problems. Students are also encouraged to travel to the department in their spare time, strengthen their communication with their classmates and teachers.

\section{Construction of Three Strong Teachers to Ensure the Quality of Clinical Rehabilitation Teaching}

\section{Raise Awareness and Strengthen Guidance to Clinical Teaching by Relevant Departments}

The biggest difference between the teaching of rehabilitation therapy and other subjects is that the discipline pays more attention to practice. Therefore, clinical rehabilitation teaching is an important link to train students to apply theory in practice and strengthen their own clinical practice ability. Clinical rehabilitation teaching plays an important role in the teaching of rehabilitation therapy. Therefore, the relevant departments and leaders should pay more attention to clinical rehabilitation teaching and give full play to their own leadership role[3]. On the basis of strengthening the hardware facilities of clinical teaching base, the software facilities of clinical rehabilitation teaching base are further strengthened.

\section{Strengthening the Construction of the Teaching Staff}

In clinical rehabilitation teaching, the construction of teaching staff is the key to the success of clinical rehabilitation teaching. In higher medical colleges, in order to improve the clinical teaching level of teachers. Some effective measures should be taken to solve the problems existing in the teaching process of some teachers, including two aspects: first, to develop the combination of medicine and education, we can choose some teachers with advanced experience to teach; The other is to invite doctors from relevant medical departments to give guidance to students in clinical rehabilitation practice, so as to strengthen the construction of teachers in clinical rehabilitation teaching.

\section{Strengthen the Sense of Responsibility and Awareness of Teachers}

In clinical rehabilitation teaching, teachers are reviewed by the rehabilitation medical teaching base and related schools, which are responsible for rehabilitation treatment teaching and talent training. In the whole clinical rehabilitation teaching. The teacher is the direct responsible person of the students, so their own teaching level and moral quality are the key to affect the whole teaching. A qualified teacher should have a strong sense of responsibility and teaching awareness. To be able to understand the significance of their own work is not Yu Li to do a good job of the work arranged by the higher authorities, can seriously organize and arrange clinical teaching content, planning. In addition, in clinical rehabilitation In teaching, teachers should have strong communication skills and be able to persuade relevant patients to cooperate with clinical rehabilitation teaching. 


\section{Strengthen the Examination System}

The examination is the indirect measurement of the teaching results by using the test questions as the measuring tool, which is an important part of the teaching examination , and has the function of evaluating, feedback, predicting and stimulating the teaching process[4].Take the ability examination as the guidance, connect with the information construction, deepen the impending. Reform of the examination for bed examination. In the course of implementing the reform, the system form standard, the unified examination standard and the ability orientation have improved the practical effect of clinical teaching of intern. The teaching management department can obtain first-hand and objective feedback information of teaching quality, which provides the basis for adjusting teaching contents and reforming teaching methods.

\section{Improve the Management System of Clinical Rehabilitation Teaching}

Because of higher medical institutions of different sizes, in medicine, teaching and research, these three aspects are not the same level, in order to ensure good results have been achieved in clinical rehabilitation teaching, the establishment cannot do without the teaching management system for medical colleges and universities can develop various management systems, such as: To management of clinical practice, teaching hospital management rules and so on to ensure clinical rehabilitation teaching management work effectively, sustained, healthy. In addition, it should further strengthen the consciousness of teaching in medical colleges, changing concepts, straighten out the relationship between teaching and medical, teaching and medical treatment Mutual coordination and common development.

\section{References}

[1]Gao Patriotic, Wang Dongguang, Lin Yongchao. 21st the Reform trend of higher Medical Education in China at the beginning of the 21st Century. [J] .higher medical education in China.2000, (4): 20.

[2]Ding Guofang. Strengthening practice Teaching Management and improving Teaching quality. [J] .higher medical education in China. 2003(3): 13.

[3]Luo Liangping, Liu Zhimin. Pay attention to the practice link and do well the clinical practice. [J] .higher medical education in China. 2003(3): 56.

[4]Chen Qinyong, Wu Xinzhong. Reflections on examination Reform in Colleges and Universities. [J] .Journal of Chongqing Jiaotong University: social Sciences Edition, 2007,7 (add 1: 34-37). 